\title{
ENFERMEIRA INTERAGINDO TERAPEUTICAMENTE COM PACIENTE IDOSA EM DEPRESSÃO CRÔNICA ${ }^{1}$
}

\author{
NURSE INTERACTING THERAPEUTICALLY WITH ELDERLY PATIENT IN CHRONIC \\ DEPRESSION \\ ENFERMERA INTERAGIENDO TERAPÉUTICAMENTE CON PACIENTE DE EDAD EN \\ DEPRESIÓN CRÓNICA
}

\author{
Vera Lúcia Mendiondo Osinaga ${ }^{2}$ \\ Maria Cecília Morais Scatena ${ }^{3}$ \\ Antonia Regina Furegato Rodrigues ${ }^{4}$
}

\begin{abstract}
RESUMO: No modelo humanista de assistência, procuramos analisar a experiência vivida por uma enfermeira interagindo com paciente em depressão crônica. Era uma paciente atendida no Núcleo de Apoio Psicossocial (NAPS), de 60 anos de idade. apresentando sintomas depressivos, próprios de sua idade, acentuados provavelmente por suas experiências de sofrimento durante o percurso de vida. Foi uma interação terapêutica visto que foi abordado o assunto de interesse da paciente le não o do interesse da enfermeira): o ritmo da comunicação foi determinado pela paciente: a enfermeira (exceto no início quando estava um pouco ansiosa) acompanhou suas comunicaçōes, aproximou-se fisicamente quando foi preciso; interveio somente nos momentos adequados; inspirou a confiança necessária para que ela pudesse falar de sentimentos intimos; ajudou-a a recuperar-se quando se mostrou muito emocionada; conduziu segura, mas com atifude compreensiva, até que a paciente se sentisse mais tranqüila para deixá-la; demonstrou que poderia ajudá-la em outros momentos caso ela sentisse necessidade. A interação atingiu seu objetivo ajudando a paciente e sendo tecnicamente adequada nos aspectos diagnóstico e terapêutico.
\end{abstract}

UNITERMOS: Depressão - Relação interpessoal - Saúde mental - Enfermagem.

ABSTRACT: In a humanist care model we searched to analyse experiences lived by nurses interacting with chronic depression patients. There was a female patient who was being assisted by Psycho-social Support Nucleus (NAP), 60 years old, presenting depressive symptoms, proper for her age, probably stressed by her suffering experiences in life. It was a therapeutic interaction as matters of the patient's interest (not the nurses interest) have been presented; the pace of communication has been determined $b$ the patient herself; the nurse (except in the very beginning when the patient was a little anxious) followed her communication, physically approaching her whenever it was necessary: intervened only at necessary moments; inspired confidence that was necessary for the patient to talk about her intimate feelings; helped her to recover when she was out of control; conducted her safely, but with comprehensive attitude until the patient felt easy to leave her: demonstrated that she could help her in other moments if she thought it was necessary. Interaction achieved its aims helping the patient and being technically adequate for therapeutic and diagnosis aspects.

KEYWORDS: Depression - Interpersonal relationship - Mental health - Nursing,

${ }^{1}$ Trabalho elaborado na disciplina Relacionamento Interpessoal Enfermeiro-Paciente. Curso de Mestrado.

${ }^{2}$ Professor Assistente da Escola de Enfermagem da Universidade Federal de Pelotas..

${ }^{3}$ Professor Doutor do DEPCH da Escola de Enfermagem de Ribeiräo Preto - USP.

${ }^{4}$ Professor Titular do DEPCH da Escola de Enfermagem de Ribeirăo Preto - USP. 
RESUMEN: En el modelo humanista de asistencia procuramos analisar la experiencia vivida por una enfermera interagiendo con paciente en depresión crónica. Era una paciente atendida en el Núcleo de Apoyo Psico-social (NAPS), de 60 años de edad, presentando sintomas depresivos, propios de su edad, acentuados probablemente por sus experiencias de sufrimiento, durante el percurso de vida. Fué una interacción terapéutica ya que fué abordado el asunto de interés de la paciente (y no el de interés de la enfermera); el ritmo de la comunicación fué determinado por la paciente: la enfermera (Excepto en el inicio cuando estava un poco ansiosa) acompañó sus comunicaciones, se aproximó físicamente cuando fué necesario; intervino solamente en los momentos adecuados: inspiró la confianza necesaria para que ella pudiese hablar de sentimientos intimos; la ayudó a recuperarse cuando se mostró bastante emocionada: condució segura, pero con actitud comprensiva, hasta que la paciente se sintiese mas tranquila para dejarla; demostró que podería ayudarla en otros momentos caso ella sintiese necesidad. La interacción alcanzó su objetivo ayudando la paciente y siendo técnicamente adecuada en los aspectos diagnósticos y terapéutica.

UNITÉRMINOS: Depresión - Relación interpersonal - Salud mental - Enfermería.

\section{INTRODUÇÃO}

O relacionamento interpessoal é inerente à condição humana, pois é o que torna possivel ao homem existir no mundo em interação com seus semelhantes e atingir seu pleno desenvolvimento.

Embora o referencial acerca do relacionamento interpessoal seja mais utilizado em Enfermagem Psiquiátrica, percebe-se que os enfermeiros, independente de área em que atuem, estão buscando algo mais do que simplesmente a execução de tarefas rotineiras. Nota-se maior preocupação em tratar as pessoas como seres humanos, ajudando-as a ter uma vida melhor, apesar das dificuldades vivenciadas no momento, geralmente por enfrentarem uma doença, um problema, uma crise, uma dor.

O relacionamento terapêutico enfermeiro-paciente não acontece por acaso. Segundo Rodrigues (1993), o encontro pode ocorrer em qualquer local e a todo momento; pode durar alguns segundos ou ter um seguimento com uma série de interaçōes; a ajuda está centrada nas ações que procuram atender às necessidades do paciente.

Assim, vale lembrar o que dizia Horta (1979): "O ENFERMEIRO É GENTE QUE CUIDA DE GENTE". O Homem é um único, portanto as diferenças de percepção têm maior valor e são de extrema importância no processo do relacionamento terapêutico.

Rodrigues (1993) considera a relação de ajuda como algo que é baseado na interação enfermeiro-paciente, ou seja, na interação da pessoa do enfermeiro com a pessoa do paciente visando ajudar o individuo a encontrar suas próprias soluções e a sair mais amadurecido do processo. 
É necessário que se tenha em mente que o relacionamento interpessoal enfermeiro-paciente desempenha o papel fundamental na assistência de enfermagem pois, na prática de nossa profissão, toda assistência ao indivíduo se processa ao nivel das relações interpessoais.

Segundo Rudio (1993), a relação de ajuda no enfoque não diretivo pretende dar ao individuo oportunidades para que se conheça como realmente é, aceitando seu próprio processo de vida e nele se inserindo a fim de utilizar os recursos pessoais, que as experiências the oferecem, para transformações construtivas de atitudes e comportamentos.

Segundo seus principios, quando alguém busca ajuda de outra pessoa capaz de prestar auxilio e que se coloca profissionalmente disposta a compreender o problema, a ajudá-lo a evoluir pessoalmente no sentido de sua melhor adaptação pessoal através da comunicação interpessoal, temos a relação de ajuda.

Neste sentido ainda, a não diretividade é uma técnica desenvolvida por Carl Rogers, através da qual espera-se uma participação ativa do facilitador, sem com isso interferir nas mensagens verbalizadas. O terapeuta não-diretivo deve criar condiçōes favoráveis para o cliente descobrir o caminho e percorrê-lo por si, fazer suas próprias descobertas e encontrar as soluções que the pareçam mais adequadas (Rogers, 1982).

Estudiosos de diversas áreas têm-se utilizado desses conhecimentos e adaptado-os à sua prática. Na enfermagem, podemos citar o estudo de Rodrigues (1996a) que propõe um modelo de Procedimento de Enfermagem de Saúde Mental (MPESM), o qual serve de orientação aos profissionais que, através de atitudes compreensivas centradas na pessoa que precisa de ajuda, estão disseminando a humanização da assistência.

Nessa perspectiva, muitos estudos têm sido realizados, dentre os quais citamos: Miranda, Rodrigues, Scatena (1996), Rodrigues (1996b), Lima, Rodrigues, 1994, Pereira, Rodrigues (1992).

Nossa experiência de rever os conceitos de desempenho do enfermeiro sob esta ótica, onde a pessoa está no centro de uma assistência humanizada, tem sido possivel por meio dos estudos das Relações Interpessoais, especialmente através da disciplina do mesmo nome do Curso de Mestrado desenvolvidos com apoio do NUPRI (Núcleo de Estudos e Pesquisas das Relações Interpessoais).

Com base no referencial teórico sobre relacionamento interpessoal centrado na pessoa, utilizando a não-diretividade, desenvolveu-se uma interação enfermeiro-paciente no Núcleo de Apoio Psicossocial (NAPS) de Ribeirão Preto, com a finalidade de colocar em prática os conhecimentos adquiridos e de poder analisá-los, segundo este referencial. 


\section{OBJETIVOS}

Analisar, com base no referencial centrado na pessoa, a experiência vivenciada por uma enfermeira interagindo com uma paciente com depressão crônica.

\section{PERCURSO METODOLÓGICO}

A interação ocorreu no NAPS (Núcleo de Apoio Psicossocial) de Ribeirão Preto. A escolha do local e do tipo de paciente ocorreu por se tratar de um dos locais de atuação profissional de enfermeira em sua cidade de origem, a qual, nesse momento, é aluna do Mestrado em Enfermagem Psiquiátrica.

Após a permissão formal da instituição, optamos por trabalhar com um paciente psiquiátrico. Não foram pré-estabelecidos sexo, idade, cor ou diagnóstico. A escolha ocorreu quando, em uma de nossas visitas ao Núcleo, permanecendo sempre no pátio de recreação, tivemos oportunidade de observar todos os pacientes. Uma delas chamou mais a atenção por ser uma pessoa que procurava ficar sempre solitária pelo cantos, não querendo participar de contatos com outras pessoas que estavam no mesmo ambiente.

Chegando perto da paciente, a enfermeira apresentou-se e falou do trabalho que iria realizar. Colocando-se à disposição da paciente, informou-lhe que estaria indo, duas vezes por semana àquele local. Imediatamente a paciente manifestou vivo interesse em conversar dizendo que se sentia muito sozinha e gostaria muito de poder desabafar um pouco sobre o grande problema que enfrentava naquele momento.

A enfermeira sentiu-se assustada e insegura, pois seria sua primeira tentativa de estabelecer uma relação de ajuda no modelo referido. Para surpresa da enfermeira, a própria paciente resolveu o impasse dizendo que gostaria muito de desabafar com ela, mas em local onde estivessem a sós, onde ela pudesse chorar e falar tudo sobre o que Ihe angustiava. Dessa forma, a enfermeira optou por realizar a entrevista no outro dia, marcando com a paciente (junto com o consentimento da paciente) local, dia e horário.

Posteriormente, a experiência foi relatada durante as discussões na disciplina de pós-graduação "Relacionamento Interpessoal Enfermeiro-paciente", tendo sido tema de reflexão e análises por parte dos docentes e pós-graduandos ali presentes.

\section{APRESENTAÇÃO E ANÁLISE DA INTERAÇÃO ENFERMEIRO-PACIENTE}

D.S.B., que nos últimos 23 anos tem sido identificada como um quadro depressivo, tem história de várias internações no Hospital das Clinicas de Ribeirão Preto desde 1974. Natural de Potirendaba, veio para o Estado de São Paulo, onde reside há alguns anos. 
Casou-se aos 18 anos, permanecendo casada até hoje. Teve uma filha, hoje com 40 anos, a qual tem 3 filhos. Atualmente, encontra-se com 60 anos de idade. Sua atividade profissional era costureira mas já está aposentada.

Há nove meses foi encaminhada para o NAPS, com queixa de depressão e por sentir muito medo.

À luz da pesquisa, o estudo depressivo perdeu seu caráter de entidade nosológica, passando a ter "a designação de um complexo de sintomas psicopatológicos sem etiologia uniforme, de um tipo de reação que pode aparecer em decorrência de diversos padecimentos de base" (Bucher, 1979).

Rozestratem (1988) considera o idoso um ser humano com todos os seus aspectos humanos estudados nas diversas ciências. Todas elas têm algo importante a dizer sobre esta fase da vida, sobre o comportamento desse individuo e sobre a maneira de ver as coisas e de agir.

No que se refere aos aspectos psicológicos do idoso, segundo Perestrello (1989), estes sintomas são mais comumente encontrados e são identificados à medida em que o envelhecimento vai tornando a pessoa mais individualizada com evidente egocentrismo, onde o interesse volta-se mais para si próprio. Alguns idosos tendem a isolar-se ou, no mínimo, a diminuir suas relações. São comuns, nos estados depressivos, os sentimentos de solidão e de inutilidade.

O sentimento de solidão tão comum nas queixas das pessoas idosas e suas dificuldades nos relacionamentos interpessoais foi por muito tempo considerado como reflexos de situações não resolvidas no passado, portanto, conseqüência de um tipo de personalidade. Segundo esta concepção, provavelmente estes sentimento sempre estiveram presentes na vida da pessoa, porém exacerbamse na velhice.

A interação com D. foi um contato, no principio, tenso para as duas partes: paciente e enfermeira. Uma querendo a pessoa certa para ouví-la e a outra com receio de não saber o que dizer, como conduzir e querendo ser o mais sensata possivel.

A reação da paciente, frente à ansiedade, foi a de falar sem parar e a da enfermeira foi a de se calar.

A verbalização da paciente foi positiva pois ela precisava desabafar como ela mesma falava. Entretanto, o silêncio da enfermeira chegou a causar na paciente a sensação de dúvida e até de certa insegurança quando percebeu que ela se calava. Ela expressou-se assim...

e.... com isso... eu... precisei tratamento psiquiátrico novamente, mas fazia o tratamento 3, 4 meses e melhorava e... depois, no ano de 1991, em agosto, eu perdi uma irmã mais nova com aneurisma, e eu tenho espasmo no rosto. $O$ médico me pediu uma tomografia e... como resultado eu tive um choque muito grande porque apareceram dois 
aneurismas e... eu não ouvia nem mais o que o médico dizia, sumia e voltava e sumia e voltava ...

eu posso continuar falando?

E - Sim Dona D., eu estou Ihe ouvindo! Tudo que a sra tiver vontade de falar, estamos aqui para tentar lhe ajudar.

D - Após o resultado da tomografia comecei a chorar muito pensando...

A paciente foi relatando sua trajetória de sofrimentos, emocionou-se e chorou. A enfermeira muito atenta ao que a paciente expressava aproximou-se; esta segurou forte sua mão e prosseguiu a narrativa, chorando ainda outra vezes, enfatizando alguns acontecimentos:

"Para mim foi horrivel enfrentar novamente esse problema.

"Eu tinha medo de ficar seqüela de hepatite, mas graças a Deus sarei, me sinto vitoriosa, sarei perfeitamente e fui ganhando mais confiança em mim... até que um dia no meu retorno na neuro, o médico perguntou como eu estava passando; eu disse que sentia muito medo e ele perguntou que medo era; eu contei e aí ele disse: não, esse medo a senhora vai tratar é na psiquiatria e vai se curar. Aquilo para mim eu criei alma nova, não era un fardo que eu iria carregar para o resto da vida. Aí fui encaminhada aqui para o NAPS, desde agosto do ano passado.

Basta falar qualquer coisa, que eu não sei, enfrentar, assim, um sofrimento normal. Aquilo me emociona... (desabafo). Por isso eu queria conversar com você hoje para poder desabafar".

A paciente chorava e a enfermeira, entendendo que ela precisava deste desabafo, acompanhou-a atentamente, porém em silêncio. Mas a paciente chorava tanto que foi preciso fazer um pequeno intervalo, ou seja, alguns minutos para que ela se recuperasse. Quando a enfermeira sentiu que ela estava melhor propôs que continuassem. Ao retomar a fala, ela disse:

D - Eéé, uma das coisas que estava me angustiando era isso. Agora eu tenho passado bem ultimamente. Às vezes eu não durmo bem a noite, mas sabe o que eu penso do sono?

E- O que a senhora pensa do sono, dona D.?

$D$ - Depois que a gente morre, a gente fica na horizontal até desaparecer e, agora que estou viva, para que ficar tanto tempo deitada? Gosto de dormir bem sim, mas não gosto de ficar deitada toda a vida não... Outro dia eu disse no grupo que dá impressão que a minha mente me pune demais para que não deixe eu fazer nada errado. 
E- Nada errado! como assim?

D - Nunca eu fiz nada errado, eu queria encontrar uma maneira de parar de exigir tanto de mim, porque eu sou uma pessoa tão exigente de mim mesma, me culpo, me martirizo.. (silêncio). $\dot{E}$... desabafei... É todos nós temos o direto de errar, mas eu não me considero com direito de erro não, nunca me considerei, desde criança.

A paciente sentindo-se mais leve e como ela mesma disse "mais aliviada..." pôde aprofundar o conteúdo de sua comunicação. Passou a falar de sentimentos, ou seja, de como interpreta o sono, a mente e de como é exigente consigo própria. Para justificar a raiz de sua conduta relata um fato que deve ter sido muito marcante na sua relação com os pais, na infância:

"Quando aprendi a fazer crochê eu apanhei duas surras. Esperei a mãe ir deitar, acendi a lamparina, peguei o crochê dela e fiz tudo, terminei o crochê dela num instantinho... no dia seguinte eu crente que ela ia ficar contente porque eu tinha feito perfeitamente o crochê, então... mas apanhei... e a noite apanhei do papai porque tinha gastado todo o querosene da lamparina.

A enfermeira estimulou-a a prosseguir falando sobre sua infância dizendo " $A$ Sra morava na campanha quando criança?" Ela foi então contando sobre a familia, os irmãos e suas relaçöes dizendo que era boa aluna, que tinha facilidade para aprender mas que sofria muito. Nesse ponto, a enfermeira deuIhe oportunidade para relatar esses fatos:

E-Sofrimento? Como assim, Dona D.?

D - Papai bebia muito, a gente não percebia que ele bebia, que era alcoólatra. Ele brigava em casa, pegava a navalha, machado, foice para matar a mamãe e a gente, às vezes eles nos obrigava a dormir todos nós numa mesma cama; às vezes ele nos colocava para a rua... a gente fingia que ia embora... mamãe abria a porta da cozinha e a gente dormia a noite inteirinha embaixo da cama. (silêncio)... então quer dizer a vida minha toda ela foi de muito sofrimento... e fui muito feliz no meu casamento, conheci meu primeiro namorado aos 18 anos de idade... Até hoje ele me pajeia... eternamente enamorados, aquele que ajuda o outro nas horas difíceis, para ver 42 anos casados. Ele foi meu primeiro e único namorado ... nos conhecemos, namoramos, noivamos $e$ casamos em 45 dias. É incrível. Mas papai brigava muito, dizia que eu estava namorando demais, então resolvemos casar.

Veja que ela falou do sofrimento mas depois de um breve silêncio ponderou até que ponto foi o sofrimento e passou a falar do casamento, da felicidade e da bondade do marido. 
Nesse ponto, ela fez novo silêncio só que já não era uma atitude que parecia de alheamento; uma espécie de viagem em que ela estava se lembrando de passagens felizes. A enfermeira respeitou sua divagação $e$, depois de alguns segundos, ela voltou a falar:

D - Estou me sentindo muito bem, já me livrei daquela angústia, eu estava muito agitada com medo de falar, das coisas, mas quando comecei a falar com você... eu agora estou bem graças a Deus e... graças a tua paciência de me ouvir também né? Isso é importante... desabafei bastante.

$E$ - É bom a gente conversar, não é mesmo? A senhora teria mais algum assunto que gostaria de estar falando?

D - No momento, não.

$E$ - Então, dona D., eu lhe agradeço, voltaremos certamente a conversar, estarei vindo aqui ao núcleo uma vez por semana e outras oportunidades vamos ter. Eu gostaria que a senhora se sentisse bem à vontade.

D - Tá, muito obrigada, e desde já eu te agradeço, porque essa nossa conversa me fez realmente muito bem... e... por você ter me dado essa oportunidade de desabafar...

E-Até logo dona D.!

D- Muito obrigado! Tchau.

É importante observar o quanto foi positiva esta interação visto que foi abordado o assunto de interesse da paciente (e não o do interesse da enfermeira). O ritmo da comunicação foi determinado pela paciente; a enfermeira (exceto no início quando estava um pouco ansiosa) acompanhou suas comunicações; aproximou-se fisicamente quando foi preciso; interveio somente nos momentos adequados; inspirou a confiança necessária para que ela pudesse falar de sentimentos intimos; ajudou-a a recuperar-se quando se mostrou muito emocionada; conduziu segura mas com atitude compreensiva até que a paciente se sentisse mais tranqüila para deixá-la; demonstrou que poderia ajudá-la em outros momentos, caso ela sentisse necessidade.

Quanto à escolha de um paciente desconhecido para a primeira interação, Travelbee (1982) afirma que há diferentes correntes de opiniōes. Alguns acreditam que a informação incluída na história do paciente pode predispor o enfermeiro. Ele pode distinguir no comportamento do paciente aquilo que não existe, por exemplo : "O paciente parece estar alucinado"! Este é um exemplo de má anotação já que o comportamento do paciente deve ser descrito e não catalogado. A enfermeira pode então interpretar certas atitudes do paciente como confirmação de uma experiência alucinatória. Isto não é correto já que, no transcurso da interação, a enfermeira pode adquirir este conhecimento pela sua própria observação.

Estando livre de pré-julgamentos, a enfermeira poderá ouví-lo objetivamente, identificar suas necessidades, ajudá-lo a compreender e a encontrar soluções 
para seu problema. Estando livre, pode ter novas percepções, novas informações em contribuir com dados antes não percebidos ou não considerados mas que podem ajudar a definir melhor o plano de assistência para o paciente.

A paciente D.S.B. apresenta um quadro de depressão, que aparenta ser proveniente da sua história de vida, a qual ela relata de maneira clara.

Revela, no curso da sessão da entrevista, estruturas do tipo culposodepressivo, acentuando-se a tristeza com matizes angustiosos, ao se sentir responsável por qualquer doença ou fato desagradável ocorrido ou que venha a ocorrer com familiares ou pessoas amigas.

Relatou, em várias oportunidades, recordações com tonalidades ainda francamente depressivas, referentes à sua criação muito severa e ao falecimento do pai, o qual era muito rigido. O mais recente é o nascimento de seu neto, filho mais novo de sua filha, a qual nasceu com problemas de formação das quais ela se culpa; disse: "fiquei muito triste e chorei muito, mas, isso já passou e não sei porque continuo a ficar triste e aflita por qualquer coisa que acontece e mesmo sem nada acontecer ..."

Analisando ainda as falas de D. S. B., foi possivel perceber muitos de seus conceitos, preconceitos e valores em relação aos aspectos de sua vida, especialmente da saúde, do trabalho, do lar e das amizades. Estes aspectos estão ligados ao seu passado e têm sua parcela de influência no estado em que se encontra hoje.

\section{CONSIDERAÇÕES FINAIS}

Por ter sido o primeiro contato com esse referencial teórico, a enfermeira sentiu-se um pouco insegura, ansiosa e preocupada ao conduzir a entrevista, principalmente tentando não ser diretiva.

O fato de conhecer um novo referencial teórico não é o suficiente para se mudar uma prática. É preciso vivenciá-la e analisá-la. Perceber as finalidades e dificuldades de cada interação, de cada intervenção de enfermagem e avaliar o nosso desempenho. Este tipo de procedimento é um avanço na enfermagem. Precisamos refletir sobre nossa conduta, sobre as temáticas que utilizamos e sobretudo sobre o que significa cada atitude que tomamos. Precisamos parar de pensar se o que estamos fazendo está, de fato, ajudando a pessoa que sofre... se o que estamos fazendo está satisfazendo-nos no intimo do nosso ser... se estamos humanizando ou coisificando a nós e a pessoa com quem nos relacionamos.

Segundo Rodrigues (1986), a primeira interação tem três finalidades: diagnóstica, terapêutica e estabelecimento de um contrato, embora nem sempre se consiga alcançar estas três finalidades em apenas um contato.

Na situação apresentada, a enfermeira atingiu duas destas três finalidades: a paciente conseguiu expressar suas angústias, temores e preocupações e a enfermeira procurou identificá-los e compreendê-la. Dessa maneira, suas 
ansiedades puderam ser trabalhadas na interação, e foi estabelecida a continuidade do processo que viria no final ajudá-la em suas necessidades.

\section{REFERÊNCIAS BIBLIOGRÁFICAS}

1. BUCHER, R.. Depressão e Melancolia. Rio de Janeiro: Zahar, 1979.

2. HORTA, V. A.. Processo de Enfermagem. São Paulo: EPU-EDUSP, 1979.

3. LIMA, M.G.; RODRIGUES, A. R. F.. Estabelecendo interações de ajuda com paciente hiperativo. R. Bras. de Enferm. p. 49-55, 1993.

4. MIRANDA, F.A.N.; RODRIGUES, A.R.F.. Relacionamento interpessoal focalizando o elemento surpresa numa interação. Nursing. v. 9, n. 101, p. 30-34, 1996.

5. PEREIRA, M.A.; RODRIGUES, A.R.F.. Relacionamento terapêutico enfermeiro-paciente num posto do INAMPS: É possivel? São Paulo: ANAIS, p. 175, 1992.

6. PERESTRELlO, D.. A medicina da Pessoa. ed. 4, Rio de Janeiro: Atheneu, 1989.

7. RODRIGUES, A.R.F. Relações interpessoais enfermeiro-paciente: análise teórica e prática com vistas à humanização da assistência em saúde mental. Ribeirão Preto, 1993. Tese (Livre-docência). Escola de Enfermagem de Ribeirão Preto, Universidade de São Paulo.

8. Dos maneras de ayuda terapeutica en enfermeria psiquiátrica y de salud mental. Horizonte de Enfermeria. v. 7, n. 2, p.15-21, $1996 \mathrm{~b}$.

9. Enfermagem Psiquiátrica: prevenção e intervenção. São Paulo: E.P.U. 1996a.

10. ROGERS, C. R.. Tornar-se pessoa. São Paulo: Martins Fontes, 1982.

11. ROZESTRATEN, R.J.A.. O idoso, suas capacidades psíquicas e o trabalho. Ciênc. E Cult., v. 40, n. 7, p. 674-4, 1988.

12. RUDIO, F.V.. Orientação nâo diretiva: na educação, no aconselhamento e na psicoterapia. Petrópolis: Vozes, 1990.

13. TRAVELBEE, J.. Interventión en enfermeria psiquiátrica. Colômbia: Carvajal S.A., 1982. 